Check for updates

Cite this: RSC Adv., 2017, 7, 22447

Received 27th February 2017 Accepted 13th April 2017

DOI: $10.1039 / c 7 r a 02425 h$

rsc.li/rsc-advances

\section{Hierarchical design of nitrogen-doped porous carbon nanorods for use in high efficiency capacitive energy storage $\uparrow$}

\author{
Mei $\mathrm{Ni}{ }^{\mathrm{a}}$ Zhenghong Huang, ${ }^{\mathrm{C}}$ Xiaoling Zhang, ${ }^{\text {*a }}$ Jinping Liu, ${ }^{\mathrm{a}}$ Liang Qiao ${ }^{\mathrm{a}}$ \\ and Wen Yang iD *ab
}

We report a novel synthesis route for creating 3D interconnected hierarchical porous nitrogen-doped carbon nanorods (3D-IPCRs) using $1 \mathrm{D}$ polyaniline nanorods as a precursor and $\mathrm{SiO}_{2}$ as a porogen. The 1D carbon nanorod/ $\mathrm{SiO}_{2}$ composites initially formed during carbonization further act as raw materials for a $\mathrm{KOH}$ activation process. After subsequent removal of the templates, as-prepared 3D-IPCRs exhibit a high specific surface area $\left(1765 \mathrm{~m}^{2} \mathrm{~g}^{-1}\right)$, a large total pore volume $\left(1.06 \mathrm{~cm}^{3} \mathrm{~g}^{-1}\right)$, an interconnected porous structure, and a moderate nitrogen doping (2.63 wt\%). This interconnectivity is beneficial to improving ion diffusion properties and electrolyte wettability. The resulting carbon exhibits a much lower impedance resistance and smaller contact angle, compared with conventional mesoporous carbon, and thus has better electric double layer performance. As obtained 3D-IPCR electrodes achieve a high specific capacitance of $302 \mathrm{~F} \mathrm{~g}^{-1}$ at a current density of $0.05 \mathrm{~A} \mathrm{~g}^{-1}$ in $6 \mathrm{M} \mathrm{KOH}$ (two-electrode system), high coulombic efficiency $(99.8 \%)$ and excellent cycling stability $(92.8 \%$ of capacitance retention after 10000 cycles) even with a high mass loading (11 $\mathrm{mg} \mathrm{cm}^{-2}$ ) and thick electrode film (300 $\left.\mu \mathrm{m}\right)$. Furthermore, the energy density of 3D-IPCRs reaches $23 \mathrm{~W} \mathrm{~h} \mathrm{~kg}^{-1}$, and the power density can be as high as $18.2 \mathrm{~kW} \mathrm{~kg}^{-1}$ when the energy density remains at $9.11 \mathrm{~W} \mathrm{~h} \mathrm{~kg}^{-1}$ in an organic electrolyte.

\section{Introduction}

Supercapacitors (SCs) based on electrical double-layer charge storage have attracted extensive attention due to their high power density, fast charge-discharge rate and long life cycle., ${ }^{\mathbf{1 , 2}}$ However, compared to lithium ion batteries, the SCs that are commercially available still cannot satisfy the requirements for large energy density. Although gravimetric capacitance as the figure-of-merit is useful for comparing fully packaged SCs, unrealistic performance may be predicted for packaged devices fabricated from small amounts of electrode materials. ${ }^{3-5}$ Experimental data have shown that there is a drop in

${ }^{a}$ Key Laboratory of Cluster Science of Ministry of Education, Beijing Key Laboratory of Photoelectronic/Electrophotonic Conversion Materials, School of Chemistry and Chemical Engineering, Beijing Institute of Technology, 5 Zhongguancun Road, Beijing 100081, P. R. China. E-mail: wenyang@bit.edu.cn; Fax: +86-10-68914780

${ }^{b}$ State Key Laboratory for Modification of Chemical Fibers and Polymer Materials, School of Material Science and Engineering, DongHua University, 2999 North Renmin Road, Shanghai 201620, China

${ }^{c}$ Laboratory of Advanced Materials, Department of Materials Science and Engineering, Tsinghua University, Beijing 100084, China

$\dagger$ Electronic supplementary information (ESI) available: SEM images, TEM images, Raman spectra, XRD patterns, XPS spectrum, thermogravimetric analysis (TGA) curve, surface concentration (in at\%) of the nitrogen and oxygen species, performance of various carbon-based ECs in aqueous electrolytes. See DOI: $10.1039 / \mathrm{c} 7 \mathrm{ra02425h}$ capacitance when the mass loading is increased..$^{\mathbf{4} 6}$ In addition, the increased weight of the electrode on the current collector will obviously determine the thickness of the electrode. ${ }^{7,8}$ It has been observed that gravimetric capacitance shrinks and the equivalent series resistance (ESR) increases on thicker electrodes because of the reduced adhesion of carbon materials in the thicker electrodes. ${ }^{9}$ In addition, electrolyte decomposition may be accelerated by loading of carbon materials on a thicker electrode, which will further deteriorate the SCs performance. ${ }^{10,11}$ Nevertheless, for the purpose of realistic applications, high mass loading (e.g. $10 \mathrm{mg} \mathrm{cm}^{-2}$ ) of active materials with thick electrode microstructures (100 to $200 \mu \mathrm{m})$ are recommended by Simon and Gogotsi. ${ }^{5}$ Therefore, it is still a great challenge to achieve good capacitance behavior at significantly high electrode material loading.

One of the strategies for increasing energy density of SCs is the use of electrode materials with high specific surface area. For that reason, activated carbon is the most used electrode material for SCs. ${ }^{12}$ Unfortunately, these advantages are severely limited by the decreased electrolyte accessibility associated with the activated carbon electrode materials used currently because most of their surface area resides in micropores. ${ }^{2,13}$ Mesoporous carbon, fabricated by templates, has also been developed as an electrode material for application in SCs due to controllable pore sizes, which are readily approachable to electrolyte ions. ${ }^{14-18}$ However, both the gravimetric capacitance and rate 
performance of nanostructured mesoporous carbon materials are restricted due to its limited surface area, disordered mesostructure and randomly connected porous structures. ${ }^{16,17,19,20}$ As Oh et al. mentioned in their study, the blind or isolated pores in the carbon framework may not be accessed by electrolytes, and random pore connection makes ion movement difficult. ${ }^{16}$

Recently, porous carbon materials with interconnected hierachical porous structures, including micropore, mesopore, and macropore, have enhanced electrochemical performance in SCs because of the improvement of ion transport through macropores and mesopores and the improvement of ion storage on the micropore scale. ${ }^{\mathbf{1 3 , 1 5 , 2 1}}$ It is believed that an interconnected porous structure not only promotes penetration of electrolyte, but also significantly shortens electron transport distance and increases the surface area of ion accessibility. ${ }^{22}$ Moreover, the morphology of carbon materials also has great influence on the performance of SCs. 1D porous carbon materials have shown enhanced capacitance, excellent rate performance, and improved stability due to their high conductivity, high surface area, and good chemical stability. ${ }^{2324}$ Another strategy for enhancing the performance of SCs is incorporation of heteroatoms in the carbon skeleton as a result of pseudocapacitance. ${ }^{25}$ Therefore, development of 1D heteroatom-doped carbon materials with interconnected hierachical porous structures are highly desired for enhance both energy density and power density of SCs.

Herein, novel 3D interconnected hierarchical porous nitrogendoped carbon nanorods (3D-IPCRs) are prepared by direct $\mathrm{KOH}$ activation of $1 \mathrm{D}$ nitrogen-doped carbon nanorod/SiO $\mathrm{S}_{2}$ composites, followed by $\mathrm{NH}_{4} \mathrm{HF}_{2}$ removal of the silica hard template. To our best knowledge, only a few reports have mentioned the synthesis of 3D-IPCRs and their application in SCs. ${ }^{23,24}$ In contrast with traditional $\mathrm{KOH}$ activation of mesoporous carbon, the presence of $\mathrm{SiO}_{2}$ during the $\mathrm{KOH}$ activation can protect and maintain the original 1D nanostructure of nitrogen-doped carbon nanorods with shortened electron and ion transport distances, and avoid nanostructure fragmentation during $\mathrm{KOH}$ activation. Moreover, the novel synthetic strategy provides an opportunity to introduce micropore into the mesopore walls to interconnect blind or isolated pores. After subsequent removal of templates, as-prepared porous carbon has high surface area $\left(1765 \mathrm{~m}^{2} \mathrm{~g}^{-1}\right)$, moderate $\mathrm{N}(2.63 \mathrm{wt} \%)$ and $\mathrm{O}(9.52 \mathrm{wt} \%)$ contents, enlarged micropore volume, increased mesopore size, additional macropores, and interconnected hierarchical porous structure. As obtained 3D-IPCRs electrodes with high mass loading $\left(11 \mathrm{mg} \mathrm{cm}^{-2}\right)$ and thick electrode film $(300 \mu \mathrm{m})$ still deliver a high specific capacity of $302 \mathrm{~F} \mathrm{~g}^{-1}$ at $0.05 \mathrm{~A} \mathrm{~g}^{-1}$ and excellent cycle stability in $6 \mathrm{M} \mathrm{KOH}$ solutions. Furthermore, the energy density of carbon nanorods reaches $23 \mathrm{~W} \mathrm{~h} \mathrm{~kg}^{-1}$, and the power density can be as high as $18.2 \mathrm{~kW} \mathrm{~kg}^{-1}$ when the energy density remains $9.11 \mathrm{~W} \mathrm{~h}$ $\mathrm{kg}^{-1}$ in an organic electrolyte.

\section{Experimental}

\section{Preparation of MeMiCP-800}

Typically, $2.0 \mathrm{~g}$ aniline was dissolved in $2 \mathrm{M} \mathrm{HCl}$ solution, followed by adding $10 \mathrm{~g}$ silica colloid solution ( $\sim 12 \mathrm{~nm}$, Ludox
HS40). The suspension was kept below $10{ }^{\circ} \mathrm{C}$ while $4.56 \mathrm{~g}$ oxidant (ammonium peroxydisulphate, APS) was added with stirring. The above suspensions was transferred to an autoclave, sealed and heated at $180{ }^{\circ} \mathrm{C}$. After drying in an evaporator, the mixture was pyrolysed at $800{ }^{\circ} \mathrm{C}$ in $\mathrm{N}_{2}$ atmosphere, and then cooled to room temperature. For the activation, a mixture of $\mathrm{KOH}$ and the prepared carbon $(\mathrm{KOH}$ : carbon $=2: 1$, weight ratio) was heated to $800{ }^{\circ} \mathrm{C}$ and kept for $1 \mathrm{~h}$ in $\mathrm{N}_{2}$ flow. The activated mixture was subsequently washed with $\mathrm{HCl}$ and deionized water until the supernatant became neutral. The silica templates were etched away by $\mathrm{NH}_{4} \mathrm{HF}_{2}$ to obtain the $3 \mathrm{D}$ IPCRs labelled as MeMiCP-800.

\section{Characterization}

Morphology was observed using transmission electron microscopy (TEM, FEI Tecnai G2 F20) and scanning electron microscopy (SEM, Hitachi S4800). X-ray diffraction (XRD) with CuKa radiation was measured using a diffractometer (Rigaku). The thermogravimetric analysis (TGA) was performed in a DTG-60 (TGA, SHIMADZU). X-ray photoelectron spectroscopy (XPS) were recorded on a Thermo Scientific ESCALab 250Xi system. The Raman spectrum was acquired on a Renishaw-2000 spectrometer. Nitrogen adsorption-desorption isotherms were measured at $77 \mathrm{~K}$ with an Autosorb-iQ2 (Quantachrome) analyzer after degassing the sample at $300{ }^{\circ} \mathrm{C}$ for $6 \mathrm{~h}$.

\section{Preparation of electrodes and electrochemical measurement}

In a three-electrode device, the supercapacitor tests of the carbon materials were measured using $\mathrm{Hg} / \mathrm{HgO}$ reference electrode and platinum foil counter electrode. The samples were mixed with acetylene black and poly(tetrafluoroethylene) (PTFE) binder in a weight ratio of $8: 1: 1$; then the slurry was loaded into $\mathrm{Ni}$ foam, and dried at $80{ }^{\circ} \mathrm{C}$. The area of the electrodes were about $1 \mathrm{~cm}^{2}$ (mass loading of active electrode: $3-5 \mathrm{mg} \mathrm{cm} \mathrm{cm}^{-2}$ ). The electrochemical behavior of electrodes was measured in $6 \mathrm{M} \mathrm{KOH}$ electrolyte. In a two-electrode cell, the samples were mixed with acetylene black and PTFE binder in a weight ratio of $8: 1: 1$ and formed into pellets ( $300 \mu \mathrm{m}$ in thickness). Then the pellets were pressed on $\mathrm{Ni}$ foam, and dried at $80{ }^{\circ} \mathrm{C}$. The twoelectrode system was assembled with two nearly identical electrodes using membrane as separator, with $6 \mathrm{M} \mathrm{KOH}$ aqueous solution as electrolyte. The mass loading of active electrode materials of MeMiCP-800 was about $11 \mathrm{mg} \mathrm{cm}^{-2}$. Two-electrode system tests with $1 \mathrm{M} \mathrm{LiPF}_{6}$ in EC/DMC used as electrolyte were conducted in a 2032-type cell. The mass loading of active elec-

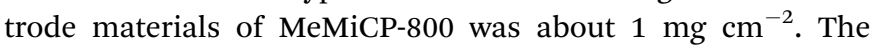
galvanostatic charge/discharge studies were measured on an Arbin testing system. Electrochemical Impedance Spectroscopy (EIS) was collected over the frequency range from $100 \mathrm{kHz}$ to $0.01 \mathrm{~Hz}$. The measured specific capacitance of acetylene black was about $7 \mathrm{~F} \mathrm{~g}^{-1}$ in $6 \mathrm{M} \mathrm{KOH}$ electrolyte in a three-electrode cell. In a three-electrode cell, the specific capacitance was calculated from:

$$
C=I t / m \Delta V
$$


where $I$ is the constant current (A), $t$ is the discharge time (s), $m$ is the active material mass in the working electrode $(\mathrm{g})$ and $\Delta V$ is the voltage change in discharge $(\mathrm{V})$. The specific capacitance $(C)$ in the two-electrode system was calculated from:

$$
C=2 I t / m \Delta V
$$

where $I$ is the constant current (A), $t$ is the discharge time (s), $m$ is the single mass of the active material in each electrode $(\mathrm{g})$ and $\Delta V$ is the voltage change in discharge (V). Energy density and power density were estimated from:

$$
\begin{gathered}
E=1 / 2 C(\Delta V)^{2} \\
P=E / t
\end{gathered}
$$

where $\Delta V$ is the voltage range after ohmic drop (V) and $t$ is the discharge time $(\mathrm{h})$.

\section{Results and discussion}

\section{Structural characterization of samples}

$\mathrm{KOH}$ activation has been used as an effective strategy to make 1D carbon materials attaining a high-surface area and porous structure. During the pyrolysis of the mixture of carbon nanorods and $\mathrm{KOH}$, the process starts with solid-solid reactions and then proceeds by solid-liquid reactions, including the oxidation of carbon to carbonate and carbon oxide, the reduction of potassium (K) compounds to form metallic $\mathrm{K}$, and other reactions among various active intermediates, leading to a surface area of even higher than $3000 \mathrm{~m}^{2} \mathrm{~g}^{-1} \cdot \mathbf{. 1 1 , 2 6}^{\mathbf{1}}$ However, it is still a challenge to use the $\mathrm{KOH}$ activation process to develop $1 \mathrm{D}$ carbon materials with porosity, especially with an interconnected hierarchical porous structure, because the original 1D nanostructures are destroyed under harsh conditions. ${ }^{27}$

To address this problem, in the present study $\mathrm{SiO}_{2}$ hard templates were used as structural support for 1D carbon materials to prevent collapse of the 1D nanostructure caused by the $\mathrm{KOH}$ activation. In contrast with traditional $\mathrm{KOH}$ activation of mesoporous carbon, the presence of $\mathrm{SiO}_{2}$ during the $\mathrm{KOH}$ activation could protect and maintain the original $1 \mathrm{D}$ nanostructures of the carbon, while suppressing nanostructures fragmentation. After subsequent etching of the silica hard templates, randomly distributed mesopores in the skeleton of carbon nanorods were enlarged and interconnected by extra micropores introduced by $\mathrm{KOH}$ activation.

The synthesis process of 3D-IHPCRs is illustrated in Scheme 1. First, aniline polymers co-assembled with colloidal silica nanoparticles are pyrolyzed at $800{ }^{\circ} \mathrm{C}$ to obtain $1 \mathrm{D}$ nitrogendoped carbon nanorod $/ \mathrm{SiO}_{2}$ composites, providing morphology control and pore size adjustability. Moreover, nitrogen-containing precursors can incorporate $\mathrm{N}$ atoms into the carbon skeleton during pyrolysis. Second, the initially formed $1 \mathrm{D}$ carbon nanorod $/ \mathrm{SiO}_{2}$ composites are directly used as raw materials for the $\mathrm{KOH}$ activation process at $800{ }^{\circ} \mathrm{C}$ without removing hard templates. It should be noted that the $1 \mathrm{D}$ nanostructures of the original carbon nanorods are maintained

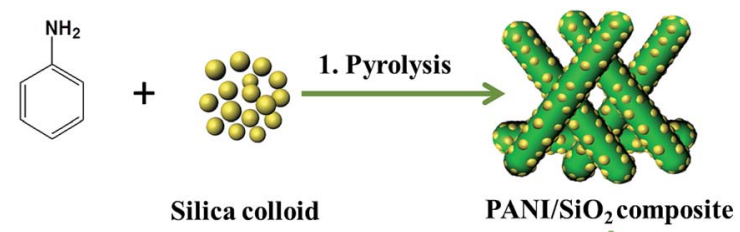

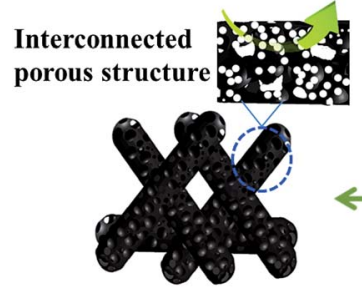

MeMiCP-800

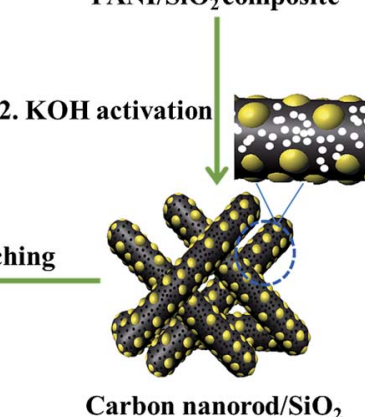

composite
Scheme 1 Illustration of the preparation of MeMiCP-800 materials.

during the $\mathrm{KOH}$ activation process probably due to the $\mathrm{SiO}_{2}$, which can help prevent the collapse of 1D nanostructures of the carbon materials in harsh reaction conditions. Third, after removing silica hard templates, micropores are introduced into the skeleton of mesoporous carbon nanorods and the mesopores are enlarged and interconnected, resulting in the desired 3D-IHPCRs labeled as MeMiCP-800. To further confirm the superior electrochemical performance of MeMICP-800, asprepared MeMiCP-800 is compared with carbon nanorods derived from polyaniline (CP), mesoporous carbon nanorods derived from polyaniline nanorod $/ \mathrm{SiO}_{2}$ composites (MeCP), and microporous carbon nanorods obtained by chemical activation of carbon nanorods (MiCP-800), as well as hierarchical porous carbon prepared by chemical activation of the carbon nanorod/ $\mathrm{SiO}_{2}$ precursor at $700{ }^{\circ} \mathrm{C}$ (MeMiCP-700). One commercial carbon black, BP2000, is used for comparison of electrochemical performance.

Fig. 1 and S1 $\uparrow$ show SEM images of MeCP, MeMiCP-800, CP, MiCP-800, and MeMiCP-700. As shown in Fig. 1a, MeCP prepared from $\mathrm{PANI} / \mathrm{SiO}_{2}$ nanorods have an average diameter of $200 \mathrm{~nm}$. The mesoporous structure of MeCP is confirmed by TEM showing that mesopores are well-developed (Fig. 1b, S2a $\dagger$ ).
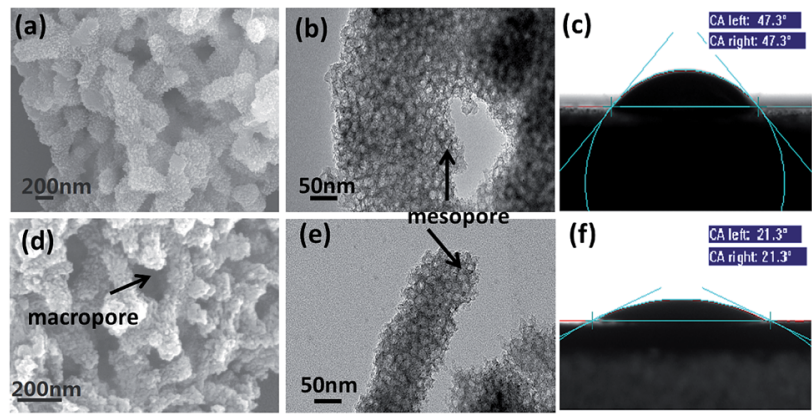

(f)

CAleft: $21.3^{3}$

Fig. 1 SEM images: (a) MeCP; (d) MeMiCP-800. TEM images: (b) MeCP; (e) MeMiCP-800. Wetting contact angles (CA) of a water droplet on (c) MeCP and (f) MeMiCP-800 substrates. 
As seen in the SEM image (Fig. 1d), MeMiCP-800 retain the original 1D nanorod shape of the PANI/SiO ${ }_{2}$. The TEM images of MeMiCP-800 highlight its 3D interconnected hierarchical porous structure and the average diameter of the nanorods decreased to $150 \mathrm{~nm}$ without obvious structural collapse (Fig. 1e and $2 \mathrm{a}$ and $\mathrm{b}$ ). The retention of the $1 \mathrm{D}$ nanorods is attributed to the sequence of experimental steps $(\mathrm{KOH}$ activation first and then removal of the template), indicating that $\mathrm{SiO}_{2}$ hard templates play an important role in maintaining the morphology. Moreover, Fig. $2 \mathrm{a}$ and $\mathrm{b}$ show that the neighboring mesopores are connected to each other after $\mathrm{KOH}$ activation and removal of the added colloidal silica. The 1D carbon nanorods with plentiful interconnected hierarchical pores (micro-, meso- and macropores) are urgently needed because they allow rapid ion diffusion. ${ }^{22}$

Raman and XRD results for samples are shown in Fig. S3. $\dagger$ All samples exhibit two characteristic peaks corresponding to Dband and G-band. The intensity ratio of $I_{\mathrm{D}} / I_{\mathrm{G}}$ obviously increases from 0.98 for MeCP to 1.03 for MeMiCP-800, indicating the increased defects after activation with $\mathrm{KOH}$. As shown in Fig. S3b, $\uparrow$ the (002) reflection in the XRD patterns can be observed at $25.2^{\circ}$ for MeCP, originating from the interlayer stacking of the graphitic layer. ${ }^{28}$ Compared to the MeCP, the (002) peak of MeMiCP-800 has slightly shifted to lower angles $\left(24.6^{\circ}\right)$ and is broadened, indicating a larger interlayer distance, and an increased disordered structure after activation which is consistent with the Raman spectral analysis. ${ }^{29}$ Meanwhile, both MeCP and MeMiCP-800 are hydrophilic and can be wetted by a water droplet (Fig. 1c and f). The contact angle of the MeCP surface is $47.3^{\circ}$. MeMiCP-800 could absorb the water droplet within its $3 \mathrm{D}$ interconnected hierarchical porous structure, demonstrating improvement of the electrolyte wettability (contact angle, $\left.\mathrm{CA}=21.3^{\circ}\right)^{30-32}$

The $\mathrm{N}_{2}$ adsorption-desorption isotherms were acquired to analyse the porosities of the resulting carbon materials (Fig. 2c).
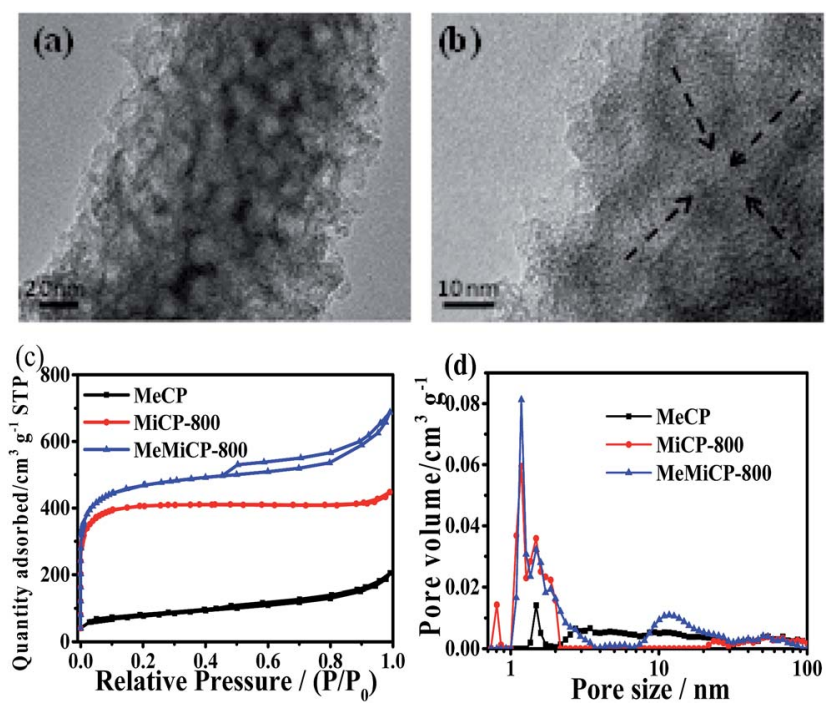

Fig. 2 (a) and (b) HRTEM image of MeMiCP-800. (c) Nitrogen adsorption-desorption isotherms and (d) pore size distributions of samples.
The Brunauer-Emmett-Teller (BET) surface areas and pore structure parameters are shown in Table 1 . It can be seen that the isotherm of MiCP-800 can be classified as a type I isotherm, revealing a microporous structure (Fig. 2c). The isotherm of MeCP exhibited type IV isotherm characteristics, and an H3 hysteresis loop can be observed, indicating the presence of mesopores in the sample. ${ }^{33-35}$ This behavior is similar to that of mesophase pitch and polyacrylonitrile-derived carbon materials using colloidal silica as a hard template, where the mesopores make up most of the total pores..$^{20,36}$ After $\mathrm{KOH}$ activation, the isotherm of MeMiCP-800 shows a combined type I/IV isotherm with strong adsorption at low pressure and an H3 hysteresis loop, indicating that micro- and mesopores coexist in the sample and form an interconnected pore system (Fig. 2c). ${ }^{37-40}$ Pore size distributions of MeCP and MeMiCP-800 obtained by the Density Functional Theory (DFT) method clearly show the increasing diameter of the mesopore due to $\mathrm{KOH}$ activation, and the mesopore volume increases from 0.24 to $0.50 \mathrm{~cm}^{3} \mathrm{~g}^{-1}$ (Fig. 2d, Table 1). In MeMiCP-800, the micropores can be readily further activated to form an interconnected pore structure via mesopore widening, wall crumbling and fusing (Fig. 2d). ${ }^{41}$ This 3D hierarchical nano-architecture of MeMiCP-800 with high specific surface area $\left(1765 \mathrm{~m}^{2} \mathrm{~g}^{-1}\right)$ and large pore volume $(1.06$ $\mathrm{cm}^{3} \mathrm{~g}^{-1}$ ) is highly desirable for energy storage and conversion than activated carbon. ${ }^{42}$

The XPS survey spectras of the MeMiCP-800 sample are shown in Fig. S4. $\dagger$ Table S1 $\uparrow$ shows nitrogen and oxygen contents of 2.63 and 9.52 at\%, respectively. The peaks around 398.1, 400.0 and $400.9 \mathrm{eV}$ correspond to pyridinic (N-6, 11.7 at\%), pyrrolic (N-5, 51.6 at\%) and quaternary (N-Q, 34.4 at\%) chemical binding states. ${ }^{43}$ This demonstrates that $\mathrm{N}$ atoms within the PANI are partly converted into N-5, N-6 or N-Q by pyrolysis. ${ }^{44}$ Owing to the incorporation of oxygen during the polymerization process of the PANI precursor and chemical activation, the existence of oxygen functional groups in the PANI-derived carbon is almost unavoidable. ${ }^{23,41}$ The deconvoluted C 1s XPS can be fit by four characteristic peaks at 284.7, $285.2,286.2$, and $288.2 \mathrm{eV}$, attributed to $\mathrm{C}-\mathrm{C}, \mathrm{C}-\mathrm{N}, \mathrm{C}-\mathrm{O}$, and $\mathrm{C}=$ $\mathrm{O}$, respectively. ${ }^{\mathbf{4 1 4 4 , 4 5}}$ The binding energies around 531.6 and $533 \mathrm{eV}$, represent $\mathrm{C}=\mathrm{O}$ quinone type groups, $\mathrm{C}-\mathrm{OH}$ phenol groups and/or $\mathrm{C}-\mathrm{O}-\mathrm{C}$ ether groups, respectively. Based on the XPS results, it is shown that $\mathrm{N}$ and $\mathrm{O}$ functional groups are contained in the carbon frame. The TGA curve of the MeMiCP800 shows complete decomposition at $616{ }^{\circ} \mathrm{C}$ (Fig. S5 $\dagger$ ), indicating that the $\mathrm{SiO}_{2}$ had been removed completely.

Table 1 Specific surface area and porosity properties of the samples

\begin{tabular}{lllll}
\hline Carbon type & $\begin{array}{l}S_{\mathrm{BET}} \\
\left(\mathrm{m}^{2} \mathrm{~g}^{-1}\right)\end{array}$ & $\begin{array}{l}S_{\text {micro }}{ }^{a} \\
\left(\mathrm{~m}^{2} \mathrm{~g}^{-1}\right)\end{array}$ & $\begin{array}{l}V_{\text {micro }}{ }^{b} \\
\left(\mathrm{~cm}^{3} \mathrm{~g}^{-1}\right)\end{array}$ & $\begin{array}{l}V_{\text {meso }}{ }^{c} \\
\left(\mathrm{~cm}^{3} \mathrm{~g}^{-1}\right)\end{array}$ \\
\hline MeCP & 272 & 71 & 0.03 & 0.24 \\
MiCP-800 & 1558 & 1285 & 0.50 & 0.10 \\
MeMiCP-800 & 1765 & 1257 & 0.49 & 0.50
\end{tabular}

${ }^{a}$ DFT micropore specific surface area (pore size $\left.<2 \mathrm{~nm}\right) .{ }^{b}$ DFT micropore volume (pore size $<2 \mathrm{~nm}) .{ }^{c}$ DFT mesopore volume $(2 \mathrm{~nm}$ $<$ pore size $<50 \mathrm{~nm}$ ). 


\section{Electrochemical performance of samples}

In order to evaluate the capacitive characteristics of the obtained carbon materials for capacitors, cyclic voltammetry (CV), galvanostatic charge/discharge (GCD) and electrochemical impedance were tested via a three-electrode device. Fig. 3a shows the CV curves of samples at the scan rate of $10 \mathrm{mV} \mathrm{s}^{-1}$. Compared with that of commercial carbon black (BP2000), the CV curves of MeMiCP-700 and MeMiCP-800 at about $-0.6 \mathrm{~V}$ display slight humps, which can be attributed to the pseudocapacitance from redox reaction of N/O functional groups, i.e. quinone group and N-6..$^{23,46,47}$ Note that as-prepared MeMiCP800 has relatively low electrochemical active N-6 contents. Thus, it may be deduced that the pseudocapacitance mainly comes from oxygen functional groups attached to the carbon, formed during the $\mathrm{KOH}$ activation process. The MeMiCP-800 retains rectangular voltammogram profiles when the scan rate is increased to $200 \mathrm{mV} \mathrm{s}^{-1}$ (Fig. 3c), indicating MeMiCP-800 has high rate capability at high scan rate. ${ }^{\mathbf{4 1}}$

The capacitive performance was further tested with GCD measurements, as shown in Fig. 3b. The specific capacitance values were calculated using eqn (1). GCD curves of the six electrodes appear nearly triangular and symmetrical, indicating good capacitive properties. ${ }^{48}$ The capacitances of the BP2000,
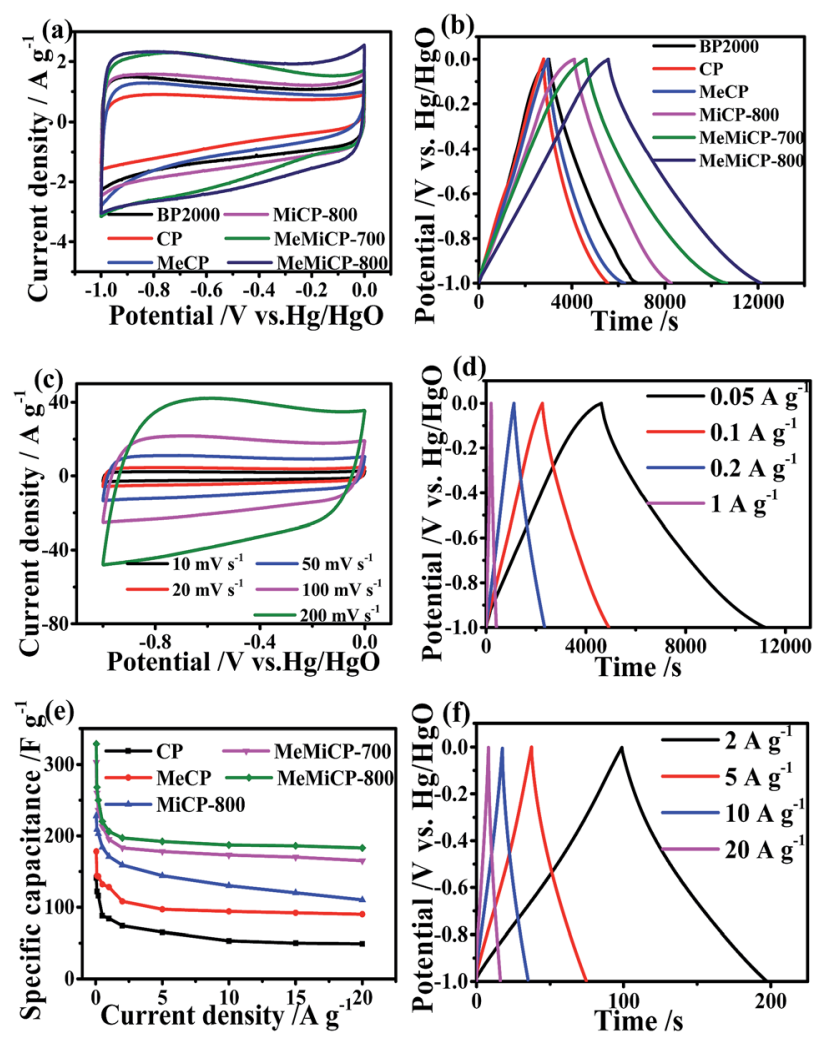

Fig. 3 Electrochemical capacitive behavior of the samples in a threeelectrode system in $6 \mathrm{M} \mathrm{KOH}$. (a) CV curves at scan rate of $10 \mathrm{mV} \mathrm{s}^{-1}$. (b) Galvanostatic charge/discharge curves at $0.05 \mathrm{~A} \mathrm{~g}^{-1}$. (c) $C V$ curves of MeMiCP-800 at different scan rates. (d) and (f) Galvanostatic charge/discharge curves of MeMiCP-800 at different current densities. (e) Specific capacitance as a function of current density ranging from 0.05 to $20 \mathrm{~A} \mathrm{~g}^{-1}$.
CP, MeCP, MiCP-800, MeMiCP-700, and MeMiCP-800 electrodes calculated from the discharge curves are 194, 141, 178, 228, 303 and $329 \mathrm{~F} \mathrm{~g}^{-1}$ at $0.05 \mathrm{~A} \mathrm{~g}^{-1}$, respectively, in good agreement with the $\mathrm{CV}$ results. The normalized capacitance of MeMiCP-800 is $18.6 \mu \mathrm{F} \mathrm{cm} \mathrm{cm}^{-2}$, which is larger than that of commercial activated carbon BP2000 (12.9 $\left.\mu \mathrm{F} \mathrm{cm}^{-2}\right)$, but smaller than that of MeCP $\left(65.4 \mu \mathrm{F} \mathrm{cm}^{-2}\right)$, indicating that the BET surface area of MeMiCP-800 were increased and micropores were introduced on the mesopore walls to interconnect blind or isolated mesopores, resulting in an enhanced double layer capacitance and electrolyte wettability, while the reduced nitrogen contents lead to the decline of pseudocapacitance, which confirmed by the decreased capacitance per unit area (Fig. S6, Table S1†). ${ }^{47}$

The rate performance was also evaluated by a three-electrode device. The specific capacitances of MeMiCP-800 in $6 \mathrm{M} \mathrm{KOH}$ are 329, 268, 206, 187 and $183 \mathrm{~F} \mathrm{~g}^{-1}$ at current densities of 0.05 , $0.1,1,10$ and $20 \mathrm{~A} \mathrm{~g}^{-1}$, respectively (Fig. $3 \mathrm{~d}$ and f). The specific capacitance of the MeMiCP-800 sample dropped by $44 \%$ (from 329 to $183 \mathrm{~F} \mathrm{~g}^{-1}$ ) as the current density increased from 0.05 to $20 \mathrm{~A} \mathrm{~g}^{-1}$, while the MeCP lost $50 \%$ of its capacitance (from 178 to $90 \mathrm{~F} \mathrm{~g}^{-1}$ ) under the identical conditions (Fig. 3e). Therefore, the interconnected hierarchical porous structures are capable of providing a short and unimpeded diffusion channel for electrolyte ions in the charge-discharge process to achieve higher capacitance and better charge/discharge rate.

As shown in the Nyquist plot (Fig. 4a), MeMiCP-800 displays low equivalent series resistance in the high frequency region, better than that of other samples. The low interface resistance may be attributed to the improved wettability of MeMiCP-800. ${ }^{25}$ The arc in the EIS diagram of MeMiCP-800 indicates a minimized charge transfer resistance in the MeMiCP-800 electrode. ${ }^{40}$ In Fig. 4 b, the corresponding relaxation time constant $\tau_{0}$ exhibits a similar trend. The MeMiCP-800 samples demonstrated a frequency response of $0.52 \mathrm{~Hz}$, higher than that of MeCP $(0.27 \mathrm{~Hz})$, corresponding to relaxation time constants $\tau_{0}$ $=1.92 \mathrm{~s}$ and $3.70 \mathrm{~s}$, respectively $\left(\tau_{0}=1 / f_{0}\right) \cdot{ }^{48,49}$ The relaxation time constant corresponds to the ion transport time in internal pores, and a smaller time constant shows easier ion diffusion. The better rate performance of the MeMiCP-800 sample is attributed to the $\mathrm{KOH}$ activation process which increased the mesopore volume from $0.24 \mathrm{~cm}^{3} \mathrm{~g}^{-1}$ to $0.50 \mathrm{~cm}^{3} \mathrm{~g}^{-1}$ and led to interconnected pore structures. ${ }^{50,51}$ The interconnected structure of MeMiCP-800 with the largest mesopore volumes further
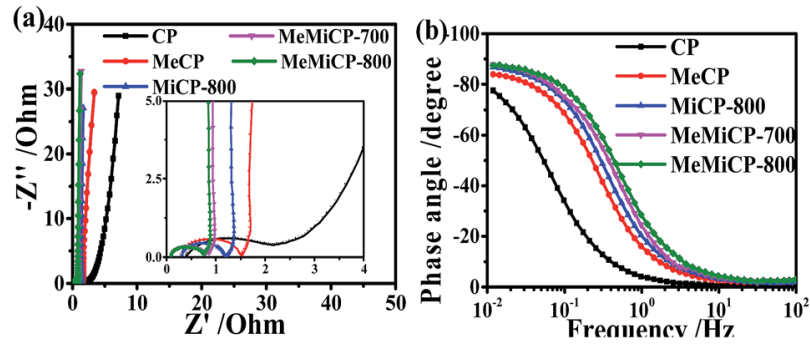

Fig. 4 (a) Nyquist plots (b) Bode plots of phase angle versus frequency of all samples measured in a three-electrode system in $6 \mathrm{M} \mathrm{KOH}$. 
favors rapid ion transport channels, leading to higher specific capacitance at high current density.

To evaluate the practical applications of MeMiCP-800 for SCs, the electrochemical behavior of MeMiCP-800 was measured in a two-electrode device using $6 \mathrm{M} \mathrm{KOH}$ and $1 \mathrm{M}$ $\mathrm{LiPF}_{6} \mathrm{EC} / \mathrm{DMC}$ as electrolytes. The CV curves of MeMiCP-800 were tested at various scan rates in the voltage window of 0 to $1 \mathrm{~V}$ and 0 to $2.5 \mathrm{~V}$ (Fig. 5a and b). All the curves display similar rectangular shape without obvious redox peaks, showing typical capacitive behavior. ${ }^{44,52}$ When the scan rate was increased to $200 \mathrm{mV} \mathrm{s}^{-1}$, the CV curves of MeMiCP-800 retained a rectangular shape with little polarization (Fig. 5a and b), indicating that the MeMiCP-800 has excellent rate performance. Fig. $5 \mathrm{c}-\mathrm{f}$ show the GCD curves of MeMiCP-800 at various current densities from 0.05 to $20 \mathrm{~A} \mathrm{~g}^{-1}$. The specific capacitance of MeMiCP800 reached 302 and $105 \mathrm{~F} \mathrm{~g}^{-1}$ at $0.05 \mathrm{~A} \mathrm{~g}^{-1}$ in $6 \mathrm{M} \mathrm{KOH}$ and $1 \mathrm{M}$ $\mathrm{LiPF}_{6} \quad$ EC/DMC electrolytes, respectively. In this study, our electrodes were $300 \mu \mathrm{m}$ in thickness, and the active electrodes had mass loadings of $11 \mathrm{mg} \mathrm{cm}^{-2}$ in aqueous electrolyte, which satisfied the suggested standard by Simon and Gogotsi. ${ }^{5}$ The curves are nearly linear, and MeMiCP-800 discharged without obvious $I R$ drop even when the current density was increased to $20 \mathrm{~A} \mathrm{~g}^{-1}$ in $\mathrm{KOH}$ electrolyte, indicating small ESR, high coulombic efficiency and excellent reversibility. MeMiCP-800 showed higher capacitive performance, especially compared
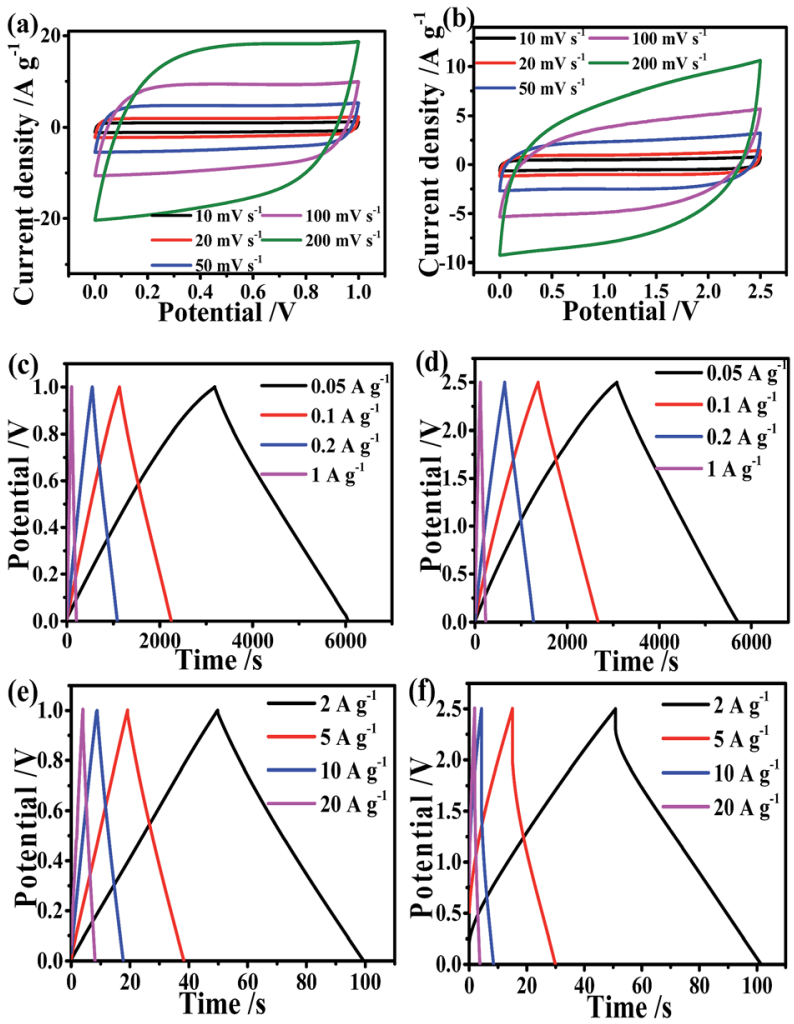

Fig. 5 Electrochemical capacitive behavior of MeMiCP-800 in a twoelectrode system. CV curves of MeMiCP-800 at different scan rates in (a) $6 \mathrm{M} \mathrm{KOH}$ and (b) $1 \mathrm{M} \mathrm{LiPF}_{6}$ EC/DMC electrolyte. Galvanostatic charge/discharge curves of MeMiCP-800 at different current densities in (c), (e) $6 \mathrm{M} \mathrm{KOH}$ and (d), (f) $1 \mathrm{M} \mathrm{LiPF}_{6} \mathrm{EC} / \mathrm{DMC}$ electrolytes.
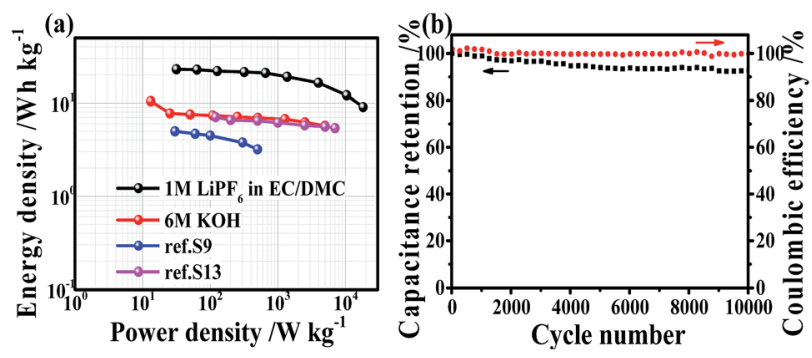

Fig. 6 (a) Ragone plots of MeMiCP-800 and other carbon-based supercapacitors in a two-electrode system. (b) Cyclability and coulombic efficiency at a current density of $1 \mathrm{~A} \mathrm{~g}^{-1}$ over 10000 cycles in a two-electrode system in $6 \mathrm{M} \mathrm{KOH}$.

with previous reports for carbon-based materials (as shown in Table S2 $\dagger$ ). The excellent electrochemical performance is attributed to the 3D interconnected hierarchical porous texture and the 1D nanostructure of MeMiCP-800, which can promote penetration of electrolyte, shorten electron transport distance and increase the surface area of ion accessibility in the capacitor.

The Ragone plot of the symmetric supercapacitor is shown in Fig. 6a. The energy density of MeMiCP-800 reaches $23 \mathrm{~W} \mathrm{~h} \mathrm{~kg}^{-1}$ in the organic electrolyte at a current density of $0.1 \mathrm{~A} \mathrm{~g}^{-1}$, which is better than that of the commercial devices $\left(<3 \mathrm{~W} \mathrm{~h} \mathrm{~kg}{ }^{-1}\right) .^{5}$ The power density of MeMiCP-800 reaches $18.2 \mathrm{~kW} \mathrm{~kg}^{-1}$ at an energy density of $9.11 \mathrm{~W} \mathrm{~h} \mathrm{~kg}^{-1}$ in organic electrolyte. In the $6 \mathrm{M}$ $\mathrm{KOH}$ electrolyte, MeMiCP-800 shows performance higher or comparable to that of other reports based on lower mass loading of electrode. The reason is that the S-doped carbon/ graphene material reported in ref. $\mathrm{S} 3 \dagger$ has low mesopore volume, and the nitrogen-doped porous carbon nanofibers reported in ref. S13 $\uparrow$ have low micropore volume. Therefore, the MeMiCP-800, which contains both large micropore and mesopore volumes, results in better performance as a supercapacitor electrode. Moreover, MeMiCP-800 shows high coulombic efficiency and $92.8 \%$ capacitance retention after 10000 consecutive cycles (Fig. 6b), indicating that the charge/discharge process of the electrode is highly invertible.

\section{Conclusions}

In summary, 3D-IPCRs with high surface area $\left(1765 \mathrm{~m}^{2} \mathrm{~g}^{-1}\right)$ and moderate $\mathrm{N}(2.63 \mathrm{wt} \%)$ and $\mathrm{O}(9.52 \mathrm{wt} \%)$ contents were fabricated by using $1 \mathrm{D}$ nitrogen-doped carbon nanorod $/ \mathrm{SiO}_{2}$ as raw materials for $\mathrm{KOH}$ activation. Compared to mesoporous carbon, the carbon materials with unique $3 \mathrm{D}$ interconnected hierarchical porous structures display better electron transport, ion diffusion, and electrolyte surface wettability, and thus have a better electric double layer performance, even at high mass loading and greater electrode thickness. Additionally, heteroatoms doping in the carbon framework could also provide pseudocapacitance, and thus can further enhance the electrochemical performance of SCs. In conclusion, our results may provide new insights for synthesis 3D-IPCRs, which are promising candidates for applications in EDLC capacitors or other electrochemical energy storage devices. 


\section{Acknowledgements}

This work was financially supported by the Natural Science Foundation of Beijing Municipality (No. 2172051), National Natural Science Foundation of China (No. 21575015, 21505004), Beijing National Laboratory for Molecular Sciences (BNLMS) (20140121), the Open Funds of the State Key Laboratory of Electroanalytical Chemistry (SKLEAC201708), Research Fund for the Doctoral Program of Higher Education of China (RFDP) (No. 20121101110049) and the 111 Project (B07012). We thank Prof. Gaoping Cao (Research Institute of Chemical Defense) for help with testing, and Prof. Zhiqiang Shi (Tianjin Polytechnic University), Prof. Shaojun Guo (Peking University), and Prof. Ruitao Lv (Tsinghua University) for useful discussions.

\section{References}

1 M. Winter and R. J. Brodd, Chem. Rev., 2004, 104, 4245-4269.

2 W. Lu, Carbon nanotubes, carbon nanotubes supercapacitors, Wiley-VCH, Germany, 2004.

3 A. Burke, Electrochim. Acta, 2007, 53, 1083-1091.

4 M. D. Stoller and R. S. Ruoff, Energy Environ. Sci., 2010, 3, 1294-1301.

5 Y. Gogotsi and P. Simon, Science, 2011, 334, 917-918.

6 L. B. Hu, J. W. Choi, Y. Yang, S. Jeong, F. L. Mantia, Y. Cui, et al., Proc. Natl. Acad. Sci. U. S. A., 2009, 106, 21490-21494.

7 S. H. Yoon, J. H. Jang, B. H. Ka and S. M. Oh, Electrochim. Acta, 2005, 50, 2255-2262.

8 C. Y. Wan, L. Y. Yuan and H. Y. Shen, Int. J. Electrochem. Sci., 2014, 9, 4024-4038.

9 S. Kumagai, K. Mukaiyachi and D. Tashima, Journal of Energy Storage, 2015, 3, 10-17.

10 Y. G. Wang, L. Cheng and Y. Y. Xia, J. Power Sources, 2006, 153, 191-196.

11 J. C. Wang and S. Kaskel, J. Mater. Chem., 2012, 22, 2371023725.

12 L. Wei and S. G. Yu, Nano Energy, 2012, 1, 552-565.

13 F. Béguin, V. Presser, A. Balducci and E. Frackowiak, Adv. Mater., 2014, 26, 2219-2251.

14 M. Sevilla, S. Álvarez, T. A. Centeno, A. B. Fuertes and F. Stoeckli, Electrochim. Acta, 2007, 52, 3207-3215.

15 Q. Zhang, F. Wei and D. W. Wang, Advanced hierarchical nanostructured materials, Wiley-VCH, 2014, pp. 443-457.

16 S. H. Yoon, J. Lee, T. Hyeon and S. M. Oh, J. Electrochem. Soc., 2000, 147, 2507-2512.

17 H. Nishihara and T. Kyotani, Adv. Mater., 2012, 24, 4473-4498.

18 W. Yang, M. Ni, X. Ren, Y. F. Tian, N. Ling, Y. F. Su, et al., Curr. Opin. Colloid Interface Sci., 2015, 20, 416-428.

19 A. H. Lu and F. Schüth, C. R. Chim., 2005, 8, 609-620.

20 J. Lee, S. J. Han and T. Hyeon, J. Mater. Chem., 2004, 14, 478486.

21 Z. Y. Yuan and B. L. Su, J. Mater. Chem., 2006, 16, 663-677.

22 Y. Liang, D. C. Wu and R. W. Fu, Langmuir, 2009, 25, 77837785.

23 W. Li, F. Zhang, Y. Q. Dou, Z. X. Wu, H. J. Liu, X. F. Qian, D. Gu, Y. Y. Xia, B. Tu and D. Y. Zhao, Adv. Energy Mater., 2011, 1, 382-386.
24 D. Y. Lee, J. Y. Jung, M. J. Jung and Y. S. Lee, Chem. Eng. J., 2015, 263, 62-70.

25 T. Q. Lin, I. W. Chen, F. X. Liu, C. Y. Yang, H. Bi, F. F. Xu, et al., Science, 2015, 350, 1508-1513.

26 L. Zhang, F. Zhang, X. Yang, G. K. Long, Y. P. Wu, T. F. Zhang, et al., Sci. Rep., 2013, 3, 1408-1417.

27 S. H. Yoon, S. Lim, Y. Song, Y. Ota, W. M. Qiao, A. Tanaka and I. Mochida, Carbon, 2004, 42, 1723-1729.

28 Y. Zhu, S. Murali, M. D. Stoller, K. J. Ganesh, W. Cai, P. J. Ferreira, et al., Science, 2011, 332, 1537-1541.

29 H. L. Wang, Z. W. Xu, A. Kohandehghan, Z. Li, K. Cui, X. H. Tan, et al., ACS Nano, 2013, 7, 5131-5141.

30 W. Wang, S. R. Guo, M. Penchev, I. Ruiz, K. N. Bozhilov, D. Yan, et al., Nano Energy, 2013, 2, 294-303.

31 M. M. Vadiyar, S. C. Bhise, S. K. Patil, S. S. Kolekar, A. R. Shelke, N. G. Deshpande, et al., Chem. Commun., 2016, 52, 2557-2560.

32 J. Zhao, H. W. Lai, Z. Y. Lyu, Y. F. Jiang, K. Xie, X. Z. Wang, et al., Adv. Mater., 2015, 27, 3541-3545.

33 G. Y. Gor, M. Thommes, K. A. Cychosz and A. V. Neimark, Carbon, 2012, 50, 1583-1590.

34 V. M. Gun'ko, Appl. Surf. Sci., 2014, 307, 444-454.

35 G. Wang, Y. H. Sun, D. B. Li, H. W. Lian, R. H. Dong, X. L. Feng, et al., Angew. Chem., Int. Ed., 2015, 54, 15191-15196.

36 Z. Li and M. Jaroniec, J. Am. Chem. Soc., 2001, 123, 9208-9209.

37 L. Zhang, X. Yang, F. Zhang, G. K. Long, T. F. Zhang, K. Leng, et al., J. Am. Chem. Soc., 2013, 135, 5921-5929.

38 L. Zhang, F. Zhang, X. Yang, G. K. Long, Y. P. Wu, T. F. Zhang, et al., Sci. Rep., 2013, 3, 1408-1417.

39 J. Pampel and T. P. Fellinger, Adv. Energy Mater., 2016, 6, 1502389-1502397.

40 S. J. Gregg and K. S. W. Sing, Adsorption, Surface Area and Porosity, Academic Press, New York, 1982.

41 X. M. Fan, C. Yu, J. Yang, Z. Ling, C. Hu and J. S. Qiu, Adv. Energy Mater., 2015, 5, 401761-401767.

42 A. Ahmadpour and D. D. Do, Carbon, 1996, 34, 471-479.

43 M. Sevilla, L. H. Yu, C. O. Ania and M. M. Titirici, ChemElectroChem, 2014, 1, 2138-2145.

44 F. B. Su, C. K. Poh, J. S. Chen, G. W. Xu, D. Wang, Q. Li, et al., Energy Environ. Sci., 2011, 4, 717-724.

45 H. Tong, W. L. Bai, S. H. Yue, Z. Z. Gao, L. Lu, L. F. Shen, S. Y. Dong, J. J. Zhu, J. P. He and X. G. Zhang, J. Mater. Chem. A, 2016, 4, 11256-11263.

46 D. W. Wang, F. Li, L. C. Yin, X. Lu, Z. G. Chen, I. R. Gentle and G. Q. Lu, Chem.-Eur. J., 2012, 18, 5345-5351.

47 B. Xu, H. Duan, M. Chu, G. P. Cao and Y. S. Yang, J. Mater. Chem. A, 2013, 1, 4565-4570.

48 C. W. Lee, S. B. Yoon, H. K. Kim, H. C. Youn, J. Han, K. C. Roh, et al., J. Mater. Chem. A, 2015, 11, 2314-2322.

49 L. L. Jiang, L. Z. Sheng, C. L. Long and Z. J. Fan, Nano Energy, 2015, 11, 471-480.

50 L. Qie, W. Chen, H. Xu, X. Xiong, Y. Jiang, F. Zou, et al., Energy Environ. Sci., 2013, 6, 2497-2504.

51 Z. J. Zhu, H. Jiang, S. J. Guo, Q. L. Cheng, Y. J. Hu and C. Z. Li, Sci. Rep., 2015, 5, 15936-15941.

52 Q. H. Liang, L. Ye, Z. H. Huang, Q. Xu, Y. Bai, F. Kanga, et al., Nanoscale, 2014, 6, 13831-13837. 